\title{
Electrophysiological correlates of monocular dominant eye perception of verbal stimuli in emotional Stroop-test
}

\author{
Mariia Rassomagina*, \\ Victoria Kravchenko, \\ Mykola Makarchuk \\ Taras Shevchenko National \\ University of Kyiv, \\ Educational and Scientific \\ Centre "Institute of Biology", \\ Academician Glushkov ave. 2, \\ 03022 Kyiv, Ukraine
}

Peculiarities of monocular analysis of emotional words through dominant eye using emotional Stroop-test were investigated. The analysis revealed an increase of beta power in right handed subjects during the task with emotional words in case of dominant eye perception. In left handed subjects an increase in theta and beta power during the same task was observed. Disappearance of difference in latency of response between left and right hand when neutral information was perceived through leading eye was shown. There is no difference in the brain dynamics during tasks with real words and meaningless words in the case of dominant eye monocular stimulation that displays ignoring of irrelevant semantic context of stimuli in the processing of information that goes through the dominant visual channel.

Key words: EEG, emotional words, dominant eye, monocular perception

\section{INTRODUCTION}

There are many papers describing the specific processing of visual stimuli perceived in the right or left side of the visual field (Van Strien, 2004; Collins, 2005). The purpose of this research was to investigate the features of information processing in the different hemispheres of

\footnotetext{
*Corresponding author. E-mail: masha_r26@ukr.net
}

the brain taking into account its functional asymmetry. The convincing theory of verbal information processing, and, in particular, processing of emotional word was formed on this basis (Abbassi et al., 2011). However, there are no works elucidating the role of dominance of the information channel for its further processing at higher levels. Could we believe that the binocular perception is a simple summation of information transmitted through the left 
and right optic tract? Is there a difference in analysis of information that contains symbols, particularly words, during performance of the tasks with the hidden meaning when applying these monocular stimuli in dominant and non-dominant eye? Finally, different neurophysiological mechanisms of information processing during monocular perception in left-handed and right-handed persons have not been studied. Peculiarities of left-handers brain's organization seem to be relevant because of differences in neuropsychiatric disorders in left-handers and right-handers with the same brain lesions. Eye dominance is the tendency to prefer visual input from one eye to input from the other (Porac, Coren, 1976). There are many versions of the sighting-eye dominance test, but the Hole-in-the-Card test, where subjects sight a target through a hole in the middle of a card, (Durand, Gould, 1910) is the most behaviorally reliable (Miles, 1928, 1929; Porac, Coren, 1976). It is suggested that there is a single sighting dominant eye for each person (Mapp, Ono, Barbeito, 2003). It was found that monocular viewing is associated with preferential activation of attention system in the contralateral to the dominant eye hemisphere (Heidi et al., 2002). Some studies have focused on the role of the superior colliculi in the generation of attention disorders, including unilateral spatial neglect (Sprague, 1966; Payne et al., 1996). Each superior colliculus receives input predominantly from the contralateral eye and each colliculus interacts with the hemisphere on the same side. Therefore, monocular viewing may preferentially activate attentional systems contralateral to the eye being used. Whereas the left hemisphere has a proximal attentional bias, the right has a distal bias (right hemisphere is dominant for attention to far space, and the left hemisphere for near space) in the right dominant subjects and vise versa for the left dominant ones (Heidi et al., 2002). The changes found with monocular viewing are thought to be related to crossed retino-tectal pathways and asymmetries in the retinogeniculate system. Studies in cats and primates have shown that the fibers from the nasal retina, which project contralaterally, outnumber the fibers from the temporal retina, which project ipsilaterally (Hubel, Wiesel, 1962; Perry et al., 1984). Nasal retina fiber diameters are also larger than temporal retinal fiber diameters and this could account for faster transmission times (Bishop et al., 1953). Therefore when only one eye is used to view a stimulus, independent of the retinal position of the viewed stimulus, the hemisphere contralateral to the viewing eye may be preferentially activated and have a processing advantage. Providing further support for this possibility, a recent fMRI study showed that contralateral occipital cortex was more activated than the ipsilateral cortex when subjects viewed flashing lights with one eye (Toosy et al., 2001). Also, it was found that dominant-eye areas are more highly activated under a non-dominant eye monocular condition than non-dominant-eye areas under a dominant-eye monocular condition (Goodyear, Menonl, 1998). Several studies concluded that for "right-eye-dominant observers" monocular stimulation of the right eye activated a greater proportion of the primary visual cortex than did stimulation of the left eye. No such asymmetry was found for "left-eyedominant observers" (Rombouts et al., 1996) probably because of more ambilateral arrangement of the verbal structures in the lefthanded persons comparing with the right-handed ones (Dobrohotova, Brahyna, 1994).

Our previous results showed that the presentation of various types of verbal stimuli was accompanied by different patterns of brain activity depending on the presentation of stimuli in the dominant or non-dominant eye in the right-handed subjects. The increase of spectral power of theta oscillations during the test with emotional words in the right-handed persons viewing through the left non-dominant eye occurred and that could reflect bigger emotional arousal. At the same time an increase of spectral power of beta oscillations was observed during analogical test in the case of viewing through dominant right eye reflecting cognitive processes controlled by top-down 
attention (Rassomagina, Kravchenko, 2013). Whereas markers of cognitive control were observed during an exposure of emotional words in the dominant eye, such stimuli did not have a pronounced effect on the subjects in these conditions or this effect was hidden by other aspects of the task. It is important to separate the contribution of dominant visual channel and asymmetric structures of hemispheres in the processing of emotional stimuli. It is known that the processing of emotional words involves both hemispheres: first left hemisphere, that is believed to be involved in the automatic analysis of the verbal information, and later right hemisphere gains access to emotional words slowly when attention is recruited by the meaning of these words (Abbassi et al., 2011).

The next task was to compare brain processing of emotional verbal stimuli in right-handers and left-handers, particularly during monocular stimulation. Comparative analysis of changes in the spectral power of EEG frequency bands while performing emotional, neutral words and pseudowords in the paradigm of emotional Stroop-test during dominant visual channel stimulation is presented in this paper.

\section{MATERIALS AND METHODS}

60 volunteers (30 right-handed and 30 lefthanded) participated in the study (university students of both sexes ( 32 males and $28 \mathrm{fe}$ males) at the age of $20 \pm 1.2$ ). According to the profile of interhemispheric asymmetry (Dobrohotova, Brahyna, 1994) participants were divided into two test groups (right-handed ones with right dominant eye and left-handed ones with left dominant eye) and two control groups (right-handed ones with right dominant eye and left-handed ones with left dominant eye). According to the above-mentioned method, handedness was assessed using visual sensorimotor reactions, such as interlocking fingers, intersection of hands (Napoleon's posture), manner of applause, watch winding, writing. Test groups performed the task using the dominant eye (non-dominant eye was covered under a special strip), control groups performed the task using binocular viewing.

Volunteers were asked to name the color of letters (red / green) as quickly as possible, when the word was presented in the center of the screen while ignoring the semantic meaning of the words and react using right or left hand accordingly. When script of the word was red they needed to push the bottom "P" on keyboard with the help of right hand, when it was green the bottom " $Q$ " - with the left one. All groups performed the task with mixed neutral (cup, spoon, jacket) and emotional (love, sex, death) words (TE), then the task with meaningless "pseudowords" (the set of letters looked like word but without meaning) (TP). The Russian-language stimuli used in the tasks consisted of equal number of letters both in words and meaningless words. All stimuli in the tasks were presented on the black front $50 \mathrm{~cm}$ from the eyes of the subject. Total amount of stimuli in both tests was 240 (120 for each hand). The size of the letters $-5 \mathrm{~mm}$. 10 minutes after the completion of the first test the subjects were asked to recall the words that they had seen on the screen. Reaction time scores (RT) (average for the left and right hands, separately for different types of stimuli - neutral, emotional, meaningless) and the number of false responses were recorded during each test. Dominant eye was determined using Hole-in-the-Card test.

In our study, we used emotional Stroop-test which is a modified version of a well known classical Stroop-test. The emotional Strooptest works by examining the response time of the participant to name colors of negative emotional words (Gotlib et al., 1984). The classic Stroop- test creates a conflict between an incongruent color and word (the word "RED" in font color blue) but the emotional Stroop involves only emotional and neutral words - color does not affect slowing because it does not conflict with the meaning of the word. In other words, the studies show the same effects of slowing for emotional words relative to neutral even if all the words are 
black. Thus, the emotional Stroop does not involve an effect of conflict between a word meaning and a color of text, but rather appears to capture attention and slow response time due to the emotional relevance of the word for the individual (Compton et al., 2003). It was shown that emotional words captured human's attention, even if they needed to ignore the semantic meaning of the words (Kissler et al., 2006). The phenomenon is evident in the increment of response time on emotional words against neutral, extending of the reaction time on neutral words that followed after "forbidden" words, better recollection of emotional words in unexpected demand, greater number of errors in tests containing emotional words, etc (MacKay et al., 2004).

EEG registration was carried out as follows: state of rest (closed eyes) - $5 \mathrm{~min}$, state of rest (opened eyes) - $2 \mathrm{~min}$, during $\mathrm{TE}-2 \mathrm{~min}$, interval between tests (opened eyes) $-2 \mathrm{~min}$, during TP $-2 \mathrm{~min}$, state of rest (closed eyes) - 2 min, using diagnostic EEG system "Neuron- Spectrum" (LTD "Neurosoft", Russia). EEG was recorded with ipsilateral ear electrode serving the reference. Electrodes were placed according to the International $10-20$ system in 16 symmetrical points of the surface of the head: prefrontal (Fp1/Fr2), medial frontal $(\mathrm{F} 3 / \mathrm{F} 4)$, lateral frontal (F7/ $\mathrm{F} 8)$, central $(\mathrm{C} 3 / \mathrm{C} 4)$, anterior $(\mathrm{T} 3 / \mathrm{T} 4)$ and posterior temporal (T5/T6), parietal (P3/ $\mathrm{P} 4)$ and occipital $(\mathrm{O} 1 / \mathrm{O} 2)$. Spectral power (SP) for the following frequency ranges: theta (4.0-7.9 Hz), alpha $(8.0-12.9 \mathrm{~Hz})$, low-beta $(13.0-19.9 \mathrm{~Hz})$, high-beta $(20.0-35.0 \mathrm{~Hz})$ was calculated with the help of "Neuron spectrum" software based on the fast Fourier transform algorithm. Epoch length was set at $2.56 \mathrm{~s}$; epoch overlap was set at $1.28 \mathrm{~s}$, bandwidth of 1-35 Hz was used.

Statistical analysis was performed using the STATISTICA 7.0 software (Statsoft, USA, 2004). Since the distribution of the most parameters obtained in these studies was different from normal Lilliefors test, Wilcoxon signedrank T-test and Mann-Whitney U-test were used. Differences were considered significant at $\mathrm{p} \leq 0.05$. Median and interquartile range was used to describe the sampling distribution (Median; 25\%; 75\%).

\section{RESULTS}

Monocular stimulation in both subjects' groups resulted in a change of SP of theta and beta oscillations in both hemispheres, indicating that processing of information received through one eye involved two hemispheres of the brain (for significantly different values of the SP of main EEG rhythm and $p$ values see Tables 1 and 2).

Growth of SP of high-frequency beta band over the prefrontal, parietal and occipital areas of both hemispheres and posterior temporal area of the left hemisphere, and lateral frontal and anterior temporal areas of the right hemisphere was found during TE performance in the right-handed group with right dominant eye (Fig. 1A). A different pattern was observed for the left-handers while viewing through left dominant eye (Fig. 1B), an increase of the SP of beta rhythm was evident over the right hemisphere, and growth SP of theta in frontooccipital region bilaterally (Fig. 2B).

EEG activity during tasks with meaningless words differed from electrical activity during state of rest with opened eyes. In this task subjects were asked to perform already familiar test with pseudowords. Increase of SP theta rhythm in the frontal and temporal areas of both hemispheres (Fig. 2B), growth of SP of low-frequency beta rhythm in the left frontal and right occipital areas and high-frequency beta rhythm in the left lateral frontal, posterior temporal, parietal, occipital areas and in the right parietal and occipital areas (Fig. 1A) was observed during the test with meaningless words as compared to pre-task state of rest in the group with right dominant eye. In the group with left dominant eye the increase of SP in the theta band and increase of SP of high-frequency beta band were observed over the right temporal and left lateral frontal areas (Fig. 1B, 2B). According to the obtained result, the task with meaningless words produced 
Table 1. Values of significantly different SP of the main EEG rhythm in right-handed subject with right dominant opened eye (Median; 25\%; 75\%)

\begin{tabular}{|c|c|c|c|}
\hline \multicolumn{4}{|c|}{$\begin{array}{l}\text { (SP) of high-frequency } \\
\text { bands of beta rhythm }\end{array}$} \\
\hline EEG leads & State of rest & $\begin{array}{l}\text { Emotional + neutral } \\
\text { words }\end{array}$ & $\mathrm{p}$ \\
\hline Fp1A1 & $10[7 ; 19]$ & $15[11 ; 19]$ & $p=0.03$ \\
\hline Fp2A2 & $13[11 ; 16]$ & $21[13 ; 29]$ & $\mathrm{p}=0.023$ \\
\hline P3A1 & $9[8 ; 15]$ & $12[9 ; 16]$ & $\mathrm{p}=0.045$ \\
\hline $\mathrm{P} 4 \mathrm{~A} 2$ & $13[10 ; 14]$ & $13[11 ; 19]$ & $\mathrm{p}=0.046$ \\
\hline O1A1 & $12[9 ; 32]$ & $18[10 ; 47]$ & $\mathrm{p}=0.043$ \\
\hline $\mathrm{O} 2 \mathrm{~A} 2$ & $14[10 ; 21]$ & $21[13 ; 38]$ & $\mathrm{p}=0.034$ \\
\hline F8A2 & $9[8 ; 15]$ & $13[9 ; 26]$ & $\mathrm{p}=0.024$ \\
\hline T4A2 & $10[8 ; 12]$ & $12[9 ; 17]$ & $\mathrm{p}=0.032$ \\
\hline T5A1 & $7[6 ; 13]$ & $10[7 ; 12]$ & $\mathrm{p}=0.012$ \\
\hline \multicolumn{4}{|c|}{$\begin{array}{l}\text { (SP) of low-frequency } \\
\text { bands of beta rhythm }\end{array}$} \\
\hline O1A1 & $9[7 ; 15]$ & $12[7 ; 17]$ & $\mathrm{p}=0.021$ \\
\hline \multicolumn{4}{|c|}{ (SP) of theta rhythm } \\
\hline EEG leads & State of rest & Pseudowords & $\mathrm{p}$ \\
\hline F4A2 & $34[24 ; 51]$ & $38[34 ; 61]$ & $\mathrm{p}=0.027$ \\
\hline F7A1 & $18[15 ; 24]$ & $20[18 ; 25]$ & $\mathrm{p}=0.043$ \\
\hline F8A2 & $20[18 ; 27]$ & $28[24 ; 50]$ & $\mathrm{p}=0.032$ \\
\hline T3A1 & $22[16 ; 28]$ & $26[18 ; 36]$ & $p=0.029$ \\
\hline T4A2 & $30[20 ; 34]$ & $33[27 ; 44]$ & $\mathrm{p}=0.035$ \\
\hline \multicolumn{4}{|c|}{$\begin{array}{l}\text { (SP) of high-frequency } \\
\text { bands of beta rhythm }\end{array}$} \\
\hline P3A1 & $10[8 ; 16]$ & $13[10 ; 21]$ & $p=0.042$ \\
\hline $\mathrm{P} 4 \mathrm{~A} 2$ & $12[10 ; 15]$ & $14[11 ; 15]$ & $\mathrm{p}=0.031$ \\
\hline O1A1 & $10[8 ; 22]$ & $18[11 ; 28]$ & $p=0.049$ \\
\hline $\mathrm{O} 2 \mathrm{~A} 2$ & $16[11 ; 26]$ & $19[13 ; 25]$ & $\mathrm{p}=0.013$ \\
\hline F7A1 & $8[6 ; 11]$ & $9[7 ; 11]$ & $\mathrm{p}=0.029$ \\
\hline T5A1 & $8[6 ; 13]$ & $9[8 ; 14]$ & $\mathrm{p}=0.035$ \\
\hline \multicolumn{4}{|c|}{ (SP) of alpha rhythm } \\
\hline $\mathrm{P} 4 \mathrm{~A} 2$ & $43[20 ; 57]$ & $31[19 ; 49]$ & $\mathrm{p}=0.038$ \\
\hline \multicolumn{4}{|c|}{$\begin{array}{l}\text { (SP) of low-frequency } \\
\text { bands of beta rhythm }\end{array}$} \\
\hline $\mathrm{O} 2 \mathrm{~A} 2$ & $11[10 ; 16]$ & $13[10 ; 18]$ & $\mathrm{p}=0.021$ \\
\hline F7A1 & $5[4 ; 7]$ & $6[5 ; 8]$ & $\mathrm{p}=0.034$ \\
\hline
\end{tabular}

substantial activation in both experimental groups.

It can be assumed that during the second test subjects expected that meaningless words would also need to be recalled, as the increase of SP of theta rhythm bilaterally over frontotemporal areas was shown to correlate with coding in working memory (Climesh, 1999; Summerfield, 2005).
Quite noteworthy was the fact that we did not find any differences in values of SP during the test with meaningless words and the test with real words in both groups. Corresponding to the experiment, the participants were divided into groups by visual dominance, it appears that brain neurodynamics did not differ in the tasks with emotional words and meaningless words in groups with dominant 




Fig. 1. Topographic maps of significant differences in spectral power (SP) of the beta rhythm in the group of right-handed subjects with the right opened dominant eye $(n=15)(A)$ and in the group of left-handed subjects with the left opened dominant eye $(n=15)(B)$ at different stages of the experiment

Note: horizontal line indicates absence of significant difference between the values of SP in respective assignments. Sign above the horizontal line - growth of rate, sign under the horizontal line - reduction of rate



opened eye (right-handers with right opened eye and left-handed with left opened one).

Herewith during normal binocular performance of the tests differences are presented. In the right-handed group the test with pseudowords was accompanied by a decrease of theta oscillations in the left centre-parietal areas and in the left-handed group by a decrease of SP beta-1 band in the temporal areas and right centre-parietal areas with parallel growth of SP alpha rhythm in the left occipital and right frontal (F4) zone. Changes in the binocular group indicate the involvement of a smaller number of brain structures in the performance of the task with pseudowords. Why such facilitation is not observed during monocular performance is the question that should be answered in the future (for significantly different values of the SP of theta rhythm and $p$ values see Tables 3 and 4).

Comparing SP of the studied EEG ranges in right-handers and left-handers during the tests performance differences in the theta range were revealed (Fig. 3). SP of theta rhythm is 


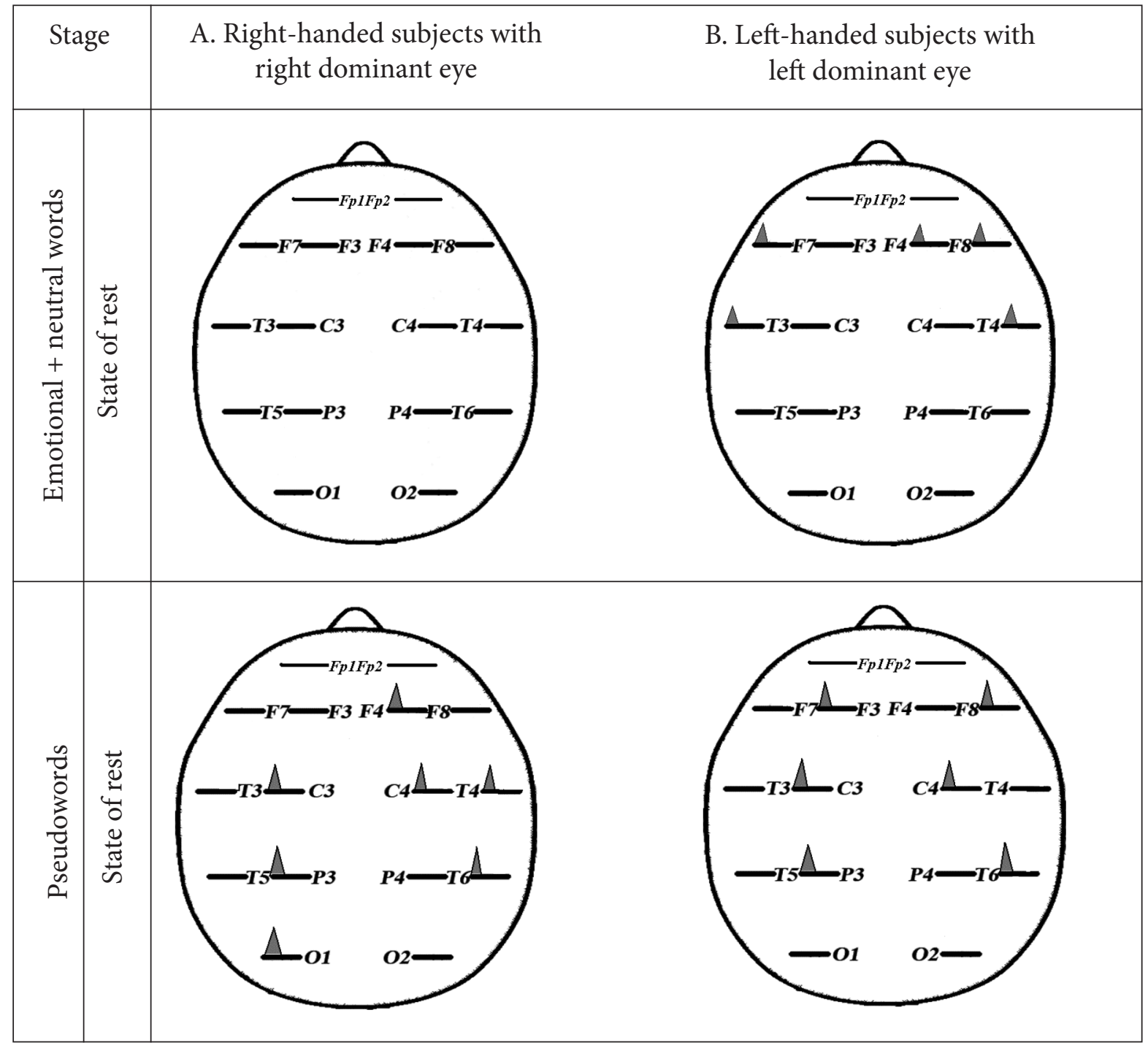

Fig. 2. Topographic maps of significant differences in spectral power (SP) of the theta rhythm in the group of right-handed subjects with the right opened dominant eye $(n=15)(A)$ and in the group of left-handed subjects with the left opened dominant eye $(n=15)(B)$ at different stages of the experiment

Note: horizontal line indicates absence of significant difference between the values of SP in respective assignments. Sign above the horizontal line - growth of rate, sign under the horizontal line - reduction of rate

smaller in the left-handed group than in the right-handed group in the right frontal and temporal areas. The exception is F8 zone - here conversely, a higher SP of theta rhythm was recorded during performance of both tests: with words (24 [20;30] (right-handers) and 34 [16; 41] (left-handers)) and with pseudowords (23 [18; 28] (right-handers) and 28 [23; 40] (left-handers)). Activation of this zone roughly corresponds to the right inferior frontal gyrus (BA 44); according to the paper (Ranganath et al., 2004), a successful encoding of a word and its font color is predicted. Comparing the number of errors in the TE test in both monocular groups we can see that the left-handers made less mistakes $(3[2 ; 6])$ than right-handers $(6[4 ; 7])$, although p-level was not significant $(\mathrm{p}=0.12)$. The number of errors in the test with meaningless words did not differ: $(4[2 ; 6])$ and $(4[1 ; 5])$ in left-handers 
Table 2. Values of significantly different SP of the main EEG rhythm in left-handed subject with left dominant opened eye (Median; 25\%; 75\%)

\begin{tabular}{|c|c|c|c|}
\hline \multicolumn{4}{|c|}{ (SP) of theta rhythm } \\
\hline EEG leads & State of rest & $\begin{array}{c}\text { Emotional + neutral } \\
\text { words }\end{array}$ & $\mathrm{p}$ \\
\hline F4A2 & $20[17 ; 27]$ & $34[16 ; 41]$ & $\mathrm{p}=0.046$ \\
\hline $\mathrm{C} 3 \mathrm{~A} 1$ & $26[20 ; 31]$ & $35[30 ; 44]$ & $\mathrm{p}=0.001$ \\
\hline $\mathrm{C} 4 \mathrm{~A} 2$ & $24[31 ; 41]$ & $33[35 ; 41]$ & $\mathrm{p}=0.008$ \\
\hline P3A1 & $24[18 ; 30]$ & $34.5[29 ; 36]$ & $\mathrm{p}=0.015$ \\
\hline $\mathrm{O} 1 \mathrm{~A} 1$ & $20[14 ; 29]$ & $26.5[18 ; 34]$ & $\mathrm{p}=0.01$ \\
\hline T4A2 & $13[8,7 ; 22]$ & $20[9,9 ; 32]$ & $\mathrm{p}=0.024$ \\
\hline T6A2 & $13[9,4 ; 25]$ & $25[10 ; 30]$ & $\mathrm{p}=0.014$ \\
\hline \multicolumn{4}{|c|}{$\begin{array}{l}\text { (SP) of low-frequency } \\
\text { bands of beta rhythm }\end{array}$} \\
\hline T3A1 & $7.4[3,7 ; 9,7]$ & $8.7[5,1 ; 12]$ & $\mathrm{p}=0.027$ \\
\hline T4A2 & $5.3[4 ; 9,1]$ & $8.6[4,3 ; 11]$ & $\mathrm{p}=0.012$ \\
\hline \multicolumn{4}{|c|}{$\begin{array}{l}\text { (SP) of high-frequency } \\
\text { bands of beta rhythm }\end{array}$} \\
\hline Fp2A2 & $13[8,5 ; 16]$ & $15[9,6 ; 23]$ & $\mathrm{p}=0.025$ \\
\hline $\mathrm{F} 4 \mathrm{~A} 2$ & $10[8,6 ; 16]$ & $12.5[7,7 ; 18]$ & $\mathrm{p}=0.034$ \\
\hline $\mathrm{C} 4 \mathrm{~A} 2$ & $10.1[7,1 ; 15]$ & $11.5[9,5 ; 17]$ & $\mathrm{p}=0.018$ \\
\hline T3A1 & $10[5,5 ; 18]$ & $14[7,4 ; 21]$ & $\mathrm{p}=0.015$ \\
\hline T4A2 & $10[4,8 ; 13]$ & $14[6,6 ; 19]$ & $\mathrm{p}=0.001$ \\
\hline T6A2 & $8.2[5,5 ; 12]$ & $14[8,6 ; 17]$ & $\mathrm{p}=0.006$ \\
\hline \multicolumn{4}{|c|}{$\begin{array}{l}\text { (SP) of high-frequency } \\
\text { bands of beta rhythm }\end{array}$} \\
\hline EEG leads & State of rest & Pseudowords & $\mathrm{p}$ \\
\hline F7A1 & $12[9,8 ; 14]$ & $14[9 ; 18]$ & $p=0.46$ \\
\hline T4A2 & $8.7[6,5 ; 17]$ & $11[6,4 ; 14]$ & $\mathrm{p}=0.04$ \\
\hline T6A2 & $9.6[7,4 ; 12]$ & $12[6,9 ; 16]$ & $\mathrm{p}=0.017$ \\
\hline \multicolumn{4}{|c|}{ (SP) of theta rhythm } \\
\hline F3A1 & $26[18 ; 38]$ & $31[24 ; 41]$ & $\mathrm{p}=0.011$ \\
\hline $\mathrm{C} 3 \mathrm{~A} 1$ & $23[19 ; 32]$ & $37[25 ; 49]$ & $\mathrm{p}=0.007$ \\
\hline $\mathrm{C} 4 \mathrm{~A} 2$ & $20[14 ; 23]$ & $30[24 ; 39]$ & $\mathrm{p}=0.02$ \\
\hline P3A1 & $23[17 ; 28]$ & $35[23 ; 38]$ & $\mathrm{p}=0.01$ \\
\hline F8A2 & $13[9,7 ; 19]$ & $18[15 ; 22]$ & $\mathrm{p}=0.034$ \\
\hline T6A2 & $18[9,5 ; 21]$ & $23[11 ; 34]$ & $p=0.003$ \\
\hline
\end{tabular}

Table 3. Values of significantly different SP of the theta rhythm in right-handed subject with right dominant opened eye and left-handed subject with left dominant opened eye during test with emotional + neutral words (Median; 25\%; 75\%)

\begin{tabular}{c|ccc}
\hline \multicolumn{5}{c}{ (SP) of theta rhythm } \\
\hline EEG leads & Right-handed subject & Left-handed subject & $\mathbf{p}$ \\
\hline Fp2A2 & $40[29 ; 44]$ & $28[15 ; 34]$ & $\mathrm{p}=0.02$ \\
\hline F4A2 & $47[35 ; 58]$ & $34[16 ; 41]$ & $\mathrm{p}=0.007$ \\
\hline F8A2 & $24[20 ; 30]$ & $34[16 ; 41]$ & $\mathrm{p}=0.029$ \\
\hline T4A2 & $34[26 ; 51]$ & $20[9,9 ; 32]$ & $\mathrm{p}=0.008$ \\
\hline T6A2 & $34[24 ; 42]$ & $20[10 ; 29]$ & $\mathrm{p}=0.015$ \\
\hline
\end{tabular}




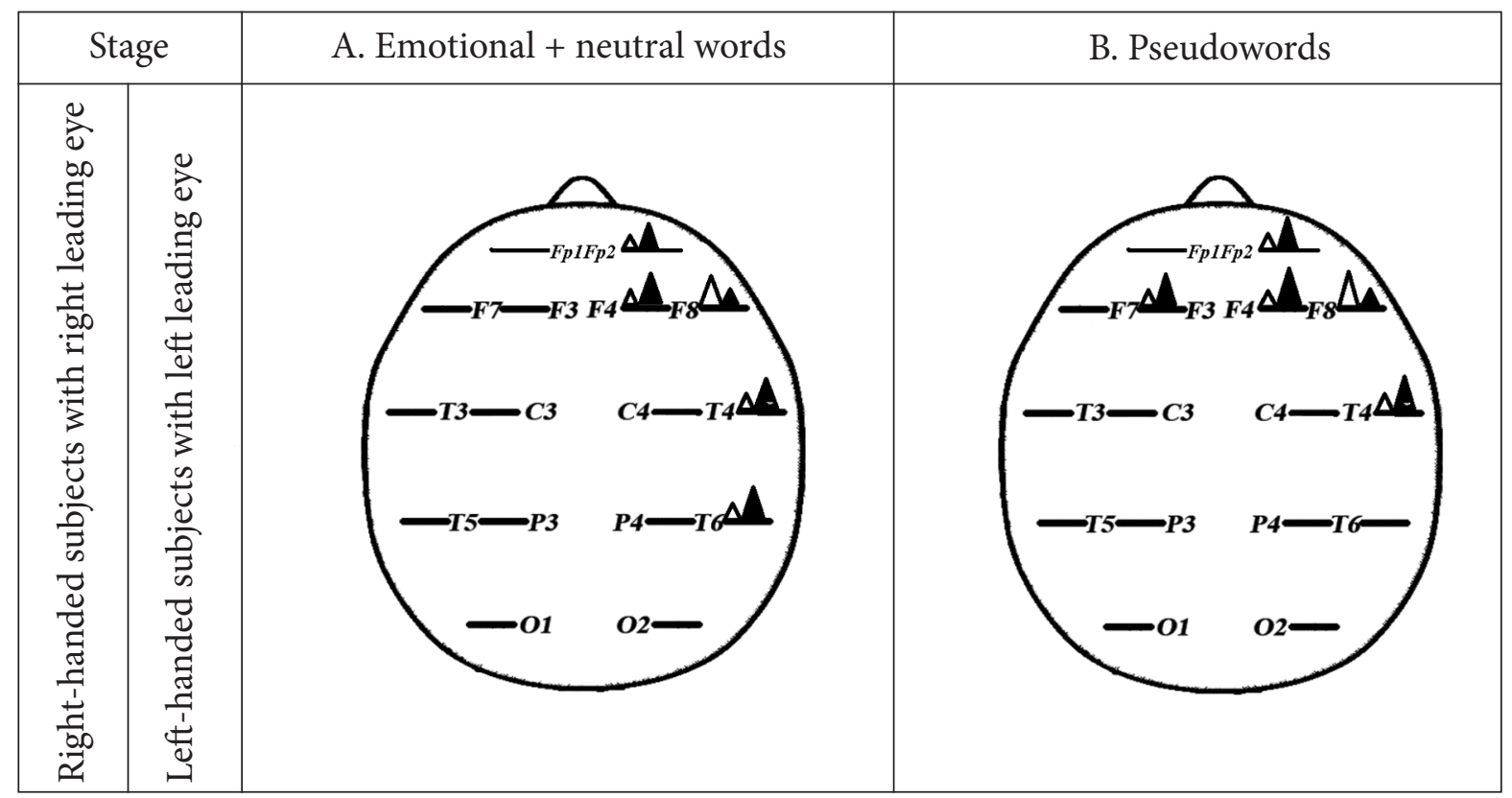

Fig. 3. Topographic maps of significant differences in spectral power (SP) of the theta rhythm in the group of right-handed subjects with right opened dominant eye $(n=15)$ and in the group of left-handed subjects with left opened dominant eye $(n=15)$ during test with real words $(A)$ and pseudowords (B)

Note: black triangle indicates significant difference between the values of SP in respective assignments in the right-handed group; white triangle indicates significant difference between the values of SP in respective assignments in the left-handed group. Big black triangle means that the value of SP in the right-handed group is bigger than the same in the left-handed group and vise versa for large white triangle

Table 4. Values of significantly different SP of the theta rhythm in right-handed subject with right dominant opened eye and left-handed subject with left dominant opened eye during test with pseudowords (Median; $25 \% ; 75 \%)$

\begin{tabular}{cccc}
\hline \multicolumn{5}{c}{ (SP) of theta rhythm } & \\
\hline EEG leads & Right-handed subject & Left-handed subject & $\mathbf{p}$ \\
\hline Fp2A2 & $38[26 ; 66]$ & $24[19 ; 37]$ & $\mathrm{p}=0.01$ \\
\hline F3A1 & $41[30 ; 56]$ & $31[24 ; 41]$ & $\mathrm{p}=0.03$ \\
\hline F4A2 & $38[34 ; 61]$ & $28[23 ; 40]$ & $\mathrm{p}=0.002$ \\
\hline F8A2 & $23[18 ; 28]$ & $28[23 ; 40]$ & $\mathrm{p}=0.0002$ \\
\hline T4A2 & $33[27 ; 44]$ & $15[10 ; 25]$ & $\mathrm{p}=0.0008$ \\
\hline
\end{tabular}

and right-handers, respectively. Therefore, at least for the test with emotional words the EEG correlate of the better processing of color of the verbal stimuli can be found - growth of SP of theta rhythm in the F8 zone that we found in more "trained" left-handers with left dominant opened eye. It seems that in the left-handed group tasks performance was accompanied by more focused activation, and in the righthanded group during tasks performance large associative networks of neurons of the right hemisphere, which is described in literature as responsible for the processing of context stimuli, in our case color, were involved.

Since the right-handers carried out the test with real words (TE) with a rise of SP theta 


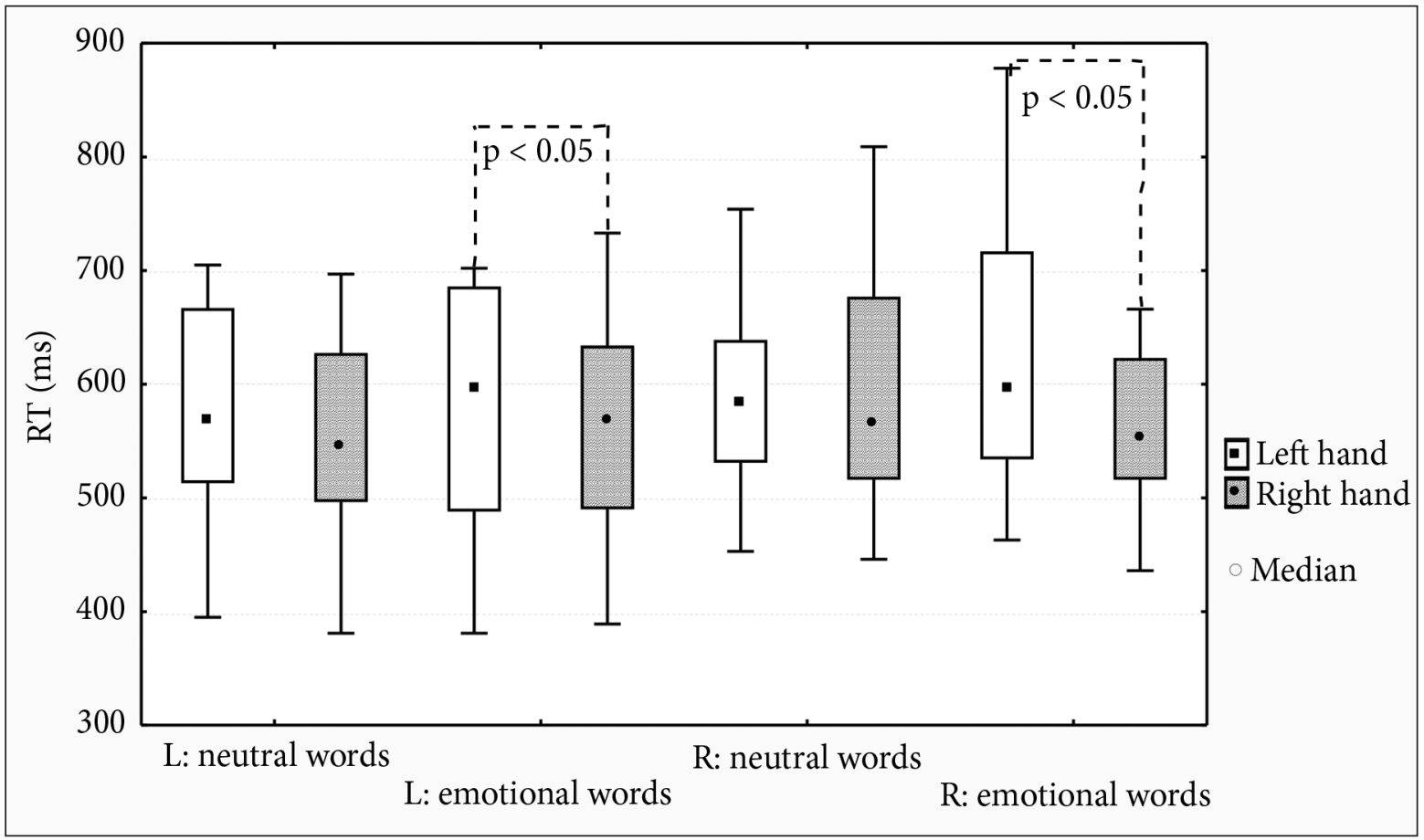

Fig. 4. Reaction time scores of responses to neutral and emotional words in groups of left-handed subjects with left dominant eye and right-handed subjects with right dominant eye

L: left-handed subjects with left dominant eye

R: right-handed subjects with right dominant eye

rhythm compared to state of rest (Fig. 2A) and during this test theta oscillations were more powerful than in the left-handers, it can be concluded that in the right-handed group theta oscillations dominated in the EEG spectrum at rest before first test performance - this may indicate that right-handers were more stressed before the test than left-handers. During the second test performance changes in the SP theta rhythm against state of rest were identical in both groups - SP grew indicating a more comfortable state of the participants in both groups before the second test, probably because of decreased novelty of the situations and tasks.

The RT scores during the test with real words that consisted of a mixture of emotional and neutral words were compared (Fig. 4). As shown in Fig. 4, there is no difference in the reaction time of the right and left hands to neutral words in both groups. Processing of emotional words led to a slower reaction of the left hand in both groups, not only in the right-handed - that is a manifestation of the phenomenon of interference - an analysis of the emotional context of verbal stimuli (provided by right hemisphere (Abbassi et al., 2011) competes with the processing of color information and that leads to a slower reaction time of the left hand, which is initiated by the right hemisphere.

We can speculate that neutral words did not catch the subject's attention when randomly presented among emotional words in the conditions of monocular perception through the dominant eye in both groups. Similar to our previous study, emotional words captured the subject's attention as evidenced by a higher percentage of recalled emotional words compared to neutral (Table 5).

\section{DISCUSSION}

Firstly, we need to outline those areas of the brain where we expected some changes in the 
Table 5. Quantity of errors and correctly recalled words after the task with real words (Median; 25\%; 75\%)

\begin{tabular}{c|ccccc}
\hline Group & \multicolumn{2}{c|}{$\begin{array}{c}\text { Number of correctly } \\
\text { reproduced words }\end{array}$} & \multicolumn{2}{c}{$\begin{array}{c}\text { Number of } \\
\text { errors }\end{array}$} \\
\hline $\begin{array}{c}\text { Right-handed subjects } \\
\text { with right leading eye }\end{array}$ & $\begin{array}{c}\text { Emotional } \\
\text { words }\end{array}$ & $\begin{array}{c}\text { Neutral } \\
\text { words }\end{array}$ & Total & $\begin{array}{c}\text { Test with real } \\
\text { words }\end{array}$ & $\begin{array}{c}\text { Test with } \\
\text { meaningless } \\
\text { words }\end{array}$ \\
\hline Right eye $(\mathrm{n}=15)$ & $4[4 ; 5]^{* *}$ & $1[1 ; 2]$ & $5[5 ; 7]$ & $6[4 ; 7]$ & $4[1 ; 5]$ \\
\hline Binocular $(\mathrm{n}=15)$ & $5[2 ; 6]^{* *}$ & $1[0 ; 2]$ & $5[3 ; 8]$ & $5[5 ; 6]^{*}$ & $3[2 ; 5]$ \\
\hline $\begin{array}{c}\text { Left-handed subjects } \\
\text { with left leading eye }\end{array}$ & $\begin{array}{c}\text { Emotional } \\
\text { words }\end{array}$ & $\begin{array}{c}\text { Neutral } \\
\text { words }\end{array}$ & Total & $\begin{array}{c}\text { Test with real } \\
\text { words }\end{array}$ & $\begin{array}{c}\text { Test with } \\
\text { meaningless } \\
\text { words }\end{array}$ \\
\hline Left eye $(\mathrm{n}=15)$ & $3[1 ; 5]^{* *}$ & $1[0 ; 2]$ & $4[1 ; 7]$ & $3[2 ; 6]$ & $4[2 ; 6]$ \\
\hline Binocular $(\mathrm{n}=15)$ & $4[2 ; 6]^{* *}$ & $0[0 ; 1]$ & $4[2 ; 6]$ & $5[2 ; 6]$ & $3[0 ; 6]$ \\
\hline
\end{tabular}

** $-\mathrm{p}<0.01$ compared to neutral words

\# $-\mathrm{p}<0.05$ compared to test with meaningless words

EEG. In the emotional Stroop-test subjects need to determine the color of the written word. However, according to literature data (Compton, 2003), the recognition of words and the assessment of their emotional significance also take place during this task. Those two processes are not the aim of the participant, but they are uncontrollable or automatic.

Identification of the semantic meaning of the word. According to neurological literature, there are brain regions that specifically respond to visual presentation of words irrespective of the task to read it. The visual word form area (VWFA) is a region in the posterior left occipitotemporal cortex adjacent to the fusiform gyrus hypothesized to mediate word recognition. The VWFA was identified (Cohen et al., 2002) as a lefthemispheric inferotemporal area showing a stronger activation to alphabetic strings than to chequerboard, and invariant for the spatial location of stimuli. In both experiments, stronger activation of the VWFA to words than to strings of consonants was observed. Considering that the VWFA is equally activated by real words and by readable pseudowords, this result demonstrates that the VWFA is initially plastic and becomes attuned to the orthographic regularities that constrain letter combination during the acquisition of literacy. According to the latest information, posterior inferior temporal gyrus takes part in the automatic analysis of the lexical words through interaction with the VWFA (Dien et al., 2013).

Emotional words processing. A growing body of literature shows that the emotional content of verbal material affects reading, wherein emotional words are given processing priority compared to neutral words (Citron, 2012). What are the parts of the brain that are often involved in the automatic analysis of emotional words? The inferotemporal cortex is implicated in directing attention toward and processing motivationally relevant stimuli (Lang et al., 1998). Amygdala and inferotemporal cortex activations are functionally integrated through dense reciprocal connections during emotional stimulus processing (Sabatinelli et al., 2005).

Also, it was shown a significant cluster of activation in the left extra-striate cortex in response to emotional than neutral words, suggesting enhanced perceptual processing of emotionally salient stimuli (Citron et al., 2014). More specifically, the dorsolateral PFC, associated with the maintenance of the attentional focus toward target features (a word's color), showed enhanced activation to incongruent color words (in the classical Stroop task) as well as to negative and highly arousing words (in the emotional Stroop task). The anterior cingulate cortex, associated with the inhibition of a salient response, was only active during the emotional Stroop task and 
showed enhanced activation for negative words than neutral ones and for high-arousal (positive and negative) words than low-arousal words (Compton et al., 2003).

Changes of SP beta rhythm. High-frequency oscillations in the EEG, which include beta and gamma bands, are interpreted in literature as a correlate of a variety of cognitive processes, which require a high level of attention (Rozumnikova, 2004). According to different authors, beta rhythm indicates the multimodal stimulus processing when association of individual characteristics of stimuli into a single unit is needed (Engel, Fries, 2010). In general, the interaction of neurons at high frequencies reflects the formation of local inter-modular neural connections for a specific signal processing, while the low-frequency rhythms (delta, theta) increase during attracting far located groups of neurons and characterize large-scale cortical integration and changes in the level of activation. Fast oscillations, therefore, favor local decisions, whereas the involvement of distant neuronal groups in distinct structures in obtaining a global consensus requires more time (Buzsáki, 2001).

The only difference between our two tasks was the type of applied stimuli: in the first case - familiar words, in the second case - meaningless words that did not have the known value for the subjects. Identification of a familiar word occurs with activation of neurons groups that represent this word in the brain and the more often it is used and more meaningful it is to the individual the easier the identification becomes. We think that meaningless words are more "energy-consuming" stimuli, as the brain has never encountered them before and tries to identify them automatically by involving relevant "card system", which forms a large number of neuronal ensembles involved in semantic analysis. The task with meaningless words was performed in the second experiment, when the strategy of task performance was formed in the first test with real words. On the one hand, the second test was easier for the participant and that is clearly seen in the reduction of reaction time on the meaningless words but, on the other hand, it probably required greater integration of cortical modules for the automatic analysis. Due to the above-mentioned information we can explain the growth of low-frequency oscillations (theta rhythm) during this task in frontal central and parietal areas of associative cortex. Growth of theta rhythm during the test with meaningless words can be interpreted also as some emotional tension or difficulties with the interpretation of these stimuli. This assumption is evidenced by the experiment where the electrical activity in the brain was investigated while listening to different types of stories. If the ending of the story is not semantically consistent with the basic content the significant growth of capacity of theta oscillations is recorded (Chen et al., 2013).

One important parameter for the generation of high-frequency oscillations in visual circuits but also in the cortex in general is the balance between excitation and inhibition. Convergence of theoretical and empirical studies indicates that the generation of high-frequency oscillations crucially involves networks of inhibitory interneurons (Mann, Paulsen, 2007; Buzsáki, Wang, 2012) and glutamatergically mediated excitatory drive. Last findings (Heng$\mathrm{Ru}, 2013$ ) suggest that excitatory / inhibitory balance by contribution of GABAergic and glutamatergic neurotransmission is crucial in assuring coordinated occurrence of high-frequency activity during normal brain functioning in networks involved in visual processing.

Growth of SP beta rhythm in the frontal areas of the brain during the test with emotional words in both groups reflects attention to a new task. Emotional Stroop test requires the development of an effective strategy to solve the basic problem (text color identification) and inhibition of brain regions that are automatically included in the analysis of the semantic meaning of words, the prefrontal cortex assumes these processes, which serves as the central executive. In particular, in his recent paper Konishi (2011) showed the role of four different areas of the frontal cortex in different types of inhibitory responses in the performance of Go / No go test for sorting the 
cards into different categories. For example, the ventrolateral part of the frontal lobe in the right hemisphere was activated during response inhibition. It can be assumed that the increase in SP beta oscillations in the right frontal areas also reflects inhibition of erroneous responses or distracting signals from areas that were "involved" in identification of words. It was shown by Bastiaansen and Hagoort (2006) that the spectral power in the beta band grows during identification of the word meaning. As participants could recall the words of the first test after it, we can state that the identification of the words occurred automatically and EEG correlate of this was the growth of SP of beta rhythm in the areas that are near to the visual word form area (VWFA) in the posterior left occipitotemporal cortex in the group with right opened eye. The important thing is that during stimulus viewing through the left eye we did not receive any activation in the beta or theta range in the occipital areas of the left hemisphere (Fig. 1B) that indicates to the different patterns of brain activity during monocular stimulation. At least in the high-frequency range of the EEG we can see the manifestation of asymmetric processing of verbal stimuli during monocular perception.

In summary, increased SP at frequencies of beta rhythm during the first task with words indicates to the process of automatic processing of verbal stimuli and their inhibition to effective determination of the text color, which requires a clear balance between excitation and inhibition in neural networks.

Evaluating the difference between activation patterns in groups with left opened eye and right opened eye it can be noted that some lateralization of brain electrical processes was observed only in the group with left opened eye - the increase of SP of beta range occurred mostly in right fronto-temporal areas. In righthanders with right dominant eye growth of highfrequency rhythms during the test with words covered both hemispheres with the exception of the right frontal area. It is important that in the control group of right-handers, binocular performance of this test was accompanied by a rise in theta, not beta oscillations. Such differences of brain processes in binocular and monocular groups suggest different ways of neurons interactions during emotional verbal stimuli processing (cooperation at different frequencies).

Changes of SP theta rhythm. Theta rhythm reflects dynamic interactions between the hippocampal system and the neocortex (Bastiaansen, 2003). The experimental evidence largely supports the hypothesis that theta activity plays a functional role in cell assembly formation, a process which may constitute the neural basis of memory formation and retrieval. Growth of SP of theta rhythm is considered as a state of readiness for information processing, is correlate of information encoding in the working memory (Klimesch, 1999) during mental stimuli reproduction (Bastiaansen, Hagoort, 2006). EEG studies using cognitive tasks have observed increased theta power during the engagement of executive functions (Brier et al., 2010), particularly in prefrontal areas. Consistent with the notion that memory processes are reflected in theta oscillations (Klimesch, 1999), language studies have shown that the theta band is sensitive to the lexical-semantic retrieval (Bastiaansen et al., 2005). Theta rhythm is also enhanced during viewing of emotionally stimuli, particularly when viewing affective images with negative valence, in such circumstances the growth of the SP of the theta rhythm is observed mostly in the temporooccipital areas (Makarchuk et al., 2011). Particularly, Il'iuchenok (1996) demonstrated AN increase of SP theta rhythm at a frequency of $7-8 \mathrm{~Hz}$ during reading of emotional words compared to neutral (both pleasant and unpleasant) bilaterally in the temporal, frontal and parietal brain regions. To summarize, theta oscillations have been found to correlate with a great variety of behavioral, cognitive and emotional variables but their main domain seems to be memory and emotional regulation (Knyazev, 2007).

Zonal changes of theta rhythm recorded in our experiment are consistent with the findings of other authors (Summerfield, Mangels, 2005), 
who investigated the EEG dynamics during analysis and memorization of verbal stimuli together with the color of their writing, although it was not the Stoop-test. Successful encoding of semantic meaning of the word stimulus is likely to demand the sharing of information between ventral stream association areas (involving visual word form area) and left frontal regions, perhaps to play a role in a semantic retrieval (Cohen et al., 2002). One possibility is that during item encoding, neurons in the left frontal structures begin to exhibit rhythmic theta activity, which, when sufficiently sustained, recruits a phase-locked response from neurons in the left posterior association areas (Summerfield, Mangels, 2005). Such activity may form a correlate of neural integration during item encoding. Whereas in fMRI study using a highly similar task noted that activation in the right inferior frontal gyrus (BA 44; roughly corresponding to the placement of our electrode F8) predicted successful encoding of a word and its font color (Ranganath et al., 2004). Spectral power analyses suggested that item + context encoding (word and color) was associated with phase locking in the theta band between frontal and posterior electrode sites bilaterally.

In our study during performing the test with meaningless words we received bilateral increase in theta rhythm in comparison with state of rest in both monocular groups, although the changes were more local in comparison with those of bilateral control groups. In general, our result is consistent with the findings of other authors who have shown that a comprehensive analysis of verbal stimuli together with the context (in this case color) occurs in parallel processing in both hemispheres - left semantic meaning, right - context, or color.

It can be inferred that the perception of words using dominant eye accompanied by increase of SP of high-frequency EEG oscillations that usually accompanies cognitive processes that are concentrated in the frontal and occipital areas. Previously, investigators found that during conflict task such as the Stroop colorword paradigm (in our task we applied the modifications of this task) cerebral blood flow in two brain regions increased: (1) in cingulofrontal system that was initially engaged in selecting and mapping a task-relevant response (color naming) when the attentional demands of the task were greatest; and (2) in the occipital-temporal areas (a ventral visual processing stream) whose concurrent decrease in activity represented the task-irrelevant inhibition of word reading (Harrison et al., 2005). Increase of SP beta rhythm is considered as a correlate of endogenous downstream processes of attention, where it is specifically focused on a particular sign stimulus (Engel, Fries, 2010). In case of non-dominant eye the differences in EEG patterns between two tests were found (according to another part of our work). There could be also another explanation. There was a thorough analysis of words in the first test and the meaningless words in the second test, as evidenced by a significant activation during TP. In favor of this fact no difference in the number of errors between the two tests for both groups of subjects who performed the task with dominant eye were found (Table 1), while in our previous studies we had shown significantly fewer numbers of errors during TP against TE for right-handed subjects when left non-dominant eye was used (Rassomagina, Kravchenko, 2013). Increase of SP theta rhythm during testing in the group of left-handers might be a marker of neuronal integration during operating with information for its storage in memory (Klimesch et al., 2008). We can assume that the perception of information through dominant eye leads to attention focusing on the task (naming the color of the words), while almost ignoring the emotional component of the stimulus. Strong increase of spectral power of beta band was observed in the right-handed group, in the left-handed group this effect was evident only over the right hemisphere and was accompanied by an increase of SP of theta rhythm. In favor of disregard for the emotional context, was the absence of differences in SP of the main rhythms during the test with meaningless words and with real words, and no difference in the number of errors between both tests. 


\section{CONCLUSIONS}

Monocular stimulation of both right and left dominant eye leads to changes of SP in theta and beta rhythms in the right and left hemispheres indicating that the processing of information received through one eye involves both hemispheres. In the case of monocular stimulation of the dominant eye of left-handers, word task performance was accompanied by the growth of SP of theta rhythm in widely distributed areas, reflecting the involvement in discrimination of emotional stimulus. In the group of right-handers, analysis of verbal stimuli was accompanied mainly by the growth of high-frequency components of EEG, indicating correlates with attention focusing on the task and inhibition of irrelevant semantic meaning of words mainly in frontal areas. The differences in reaction time and the number of errors between right-handers and left-handers were not found, reflecting the usage of different information processing strategies to achieve the same result. No difference in RTs between left and right hand to neutral information when perceived through dominant eye was found and that could indicate ignoring of semantic context of stimuli. No differences in brain dynamics during tasks with real words and meaningless words in the case of dominant eye monocular stimulation were found pointing to ignoring of irrelevant semantic context of stimuli in the processing of information that goes through the dominant visual channel.

Received 30 April 2014

Accepted 05 June 2014

\section{References}

1. Abbassi E, Kahlaoui K, Wilson M, Joanette Y. Processing the emotions in words: the complementary contributions of the left and right hemispheres. Cogn Affect Behav Neurosci 2011; 11: 372-85.

2. Bastiaansen $M$, Hagoort P. Event-Induced Theta Responses as a Window on the Dyna- mics of Memory. Cortex 2003; 39(4-5): $967-$ 92.

3. Bastiaansen M, Hagoort P. Oscillatoryneuronal dynamics during language comprehension. Prog Brain Res 2006; 159: 179-96.

4. Bastiaansen $M$, van der Linden $M$, Ter Keurs M, Dijkstra T, Hagoort P. Theta responses are involved in lexical-semantic retrieval during language processing. J Cogn Neurosci 2005; 17(3): 530-41.

5. Bishop P, Jeremy D, Lance J. The optic nerve. Properties of a central tract. J Physiol (Lond) 1953; 121: 415-32.

6. Brier M, Ferree T, Maguire M, Moore P, Spence J, Tillman G, Hart J, Kraut M. Frontal theta and alpha power and coherence changes are modulated by semantic complexity in Go / No Go tasks. Int J Psychophysiol 2010 Dec; 78(3): 215-24.

7. Buzsáki G. Electrical Wiring of the Oscillating Brain. Neuron 2001; 31(3-16): 342-4.

8. Chen X, Yuan J, Guo J, You Y. Neural oscillatory evidence of the difference between emotional and conceptual processing in language comprehension. Neurosci Lett 2013 Oct 11; 553: 159-64.

9. Citron F. Neural correlates of written emotion word processing: a review of recent electrophysiological and hemodynamic neuroimaging studies. Brain Lang 2012; 122(3): 211-26.

10. Citron F, Gray M, Critchley H, Weekes B, Ferstl E. Emotional valence and arousal affect reading in an interactive way: Neuroimaging evidence for an approach-withdrawal framework. Neuropsychologia 2014 Jan 15; 56C: 79-89.

11. Cohen L, Lehéricy S, Chochon F, Lemer C, Rivaud $S$, Dehaene $S$. Language-specific tuning of visual cortex? Functional Properties of the Visual Word Form Area. Brain 2002 May; 125: 1054-69.

12. Collins M, Cooke A. A transfer appropriate processing approach to investigating implicit memory for emotional words in the cerebral 
hemispheres. Neuropsychologia 2005; 43: 1529-45.

13. Compton J, Banich T, Mohanty A, Milham P, Herrington J, Miller A, Scalf E, Webb A. Paying attention to emotion: an fMRI investigation of cognitive and emotional Stroop tasks. Cogn Affect Behav Neurosci 2003; 3(2): 81-96.

14. Dien J, Brian E, Molfese D, Gold B. Combined ERP / fMRI evidence for early word recognition effects in the posterior inferior temporal gyrus. Cortex 2013 Oct; 49(9): 2307-21.

15. Dobrohotova T, Bragina N. The left-handers. Book 1994; 231.

16. Dobrohotova T, Bragina N. The functional asymmetry of the human. Medicine 1988; 240.

17. Durand A, Gould G. A method of determining ocular dominance. J Amer Medic Assoc 1910; 55: 369-70.

18. Engel A, Fries P. Beta-band oscillations - signalling the status quo? Curr Opin Neurobiol 2010; 20(2): 156-65.

19. Goodyear B, Menonl R. EPI BOLD fMRI Reveals Ocular Dominance Dependence on Dominant Eye. 6th Annual Meeting, International Society of Magnetic Resonance in Medicine, Sydney, 1998.

20. Gotlib H, McCann C, Douglas C. Construct accessibility and depression: An examination of cognitive and affective factors. J Person Social Psychol 1984; 47(2): 427-39.

21. Harrison B, Shaw M, Yucel M. Functional connectivity during Stroop task performance. Neuroimage 2005; 24(1): 181-91.

22. Heidi L, Roth H, Andrea N. Lora effect of monocular viewing and eye dominance on spatial attention. Brain 2002; 125: 2023-35.

23. Heng-Ru May Tan, Luiz Lana, Peter J. Uhlhaas. Front Psychol 2013; 4: 621.

24. Hubel D, Wiesel T. Receptive fields, binocular interaction and functional architecture in the cat's visual cortex. J Physiol (Lond) 1962; 160: 106-54.
25. Kissler J, Assadollahi R, Herbert C. Emotional and semantic networks in visual word processing: insights from ERP studies. Prog Brain Res 2006; 156: 147-83.

26. Klimesch W. EEG alpha and theta oscillations reflect cognitive and memory performance: a review and analysis. Brain Res Rev 1999 Apr; 29(2-3): 169-95.

27. Klimesch W, Freunberger R, Sauseng P, Gruber W. A short review of slow phase synchronization and memory: evidence for control processes in different memory systems? Brain Res 2008; 1235: 31-44.

28. Knyazev G. Motivation, emotion, and their inhibitory control mirrored in brain oscillations. Neurosci Biobehav Rev 2007; 31(3): 377-95.

29. Konishi S. Frontal lobes and inhibitory function. Brain Nerve 2011 Dec; 63(12): 1346-51.

30. Il'iuchenok I. Differences in the EEG frequency characteristics during the perception of positive-emotional, negative-emotional and neutral words. Zh Vyssh Nerv Deiat Im I P Pavlova 1996 May-Jun; 46(3): 457-68.

31. MacKay D, Shafto M, Taylor J, Marian D, Abrams L, Dyer J. Relations between emotion, memory, and attention: evidence from taboo stroop, lexical decision, and immediate memory tasks. Mem Cognit 2004; 32(3): 474-88.

32. Makarchuk N, Maksimovich K, Kravchenko V, Kryzhanovskii S. Modifications of EEG Activity Related to Perception of Emotionally Colored, Erotic, and Neutral Pictures in Women during Different Phases of the Ovulatory (Menstrual) Cycle. Neurophysiology 2011; 42(5): 362-70.

33. Mapp A, Ono H, Barbeito R. What does the dominant eye dominate? A brief and somewhat contentious review. Percept Psychophys 2003; 65: $310-17$.

34. Miles W. Ocular dominance: methods and results. Psych Bull 1928; 25: 155-6.

35. Miles W. Ocular dominance demonstrated by unconscious sighting. J Exper Psychol 1929; 12: 113-26. 
36. Payne B, Lomber S, Geeraerts S, Gucht E, Vandenbussche E. Reversible visual hemineglect. Proc Natl Acad Sci USA 1996; 93: 290-4.

37. Perry V, Oehler R, Cowey A. Retinal ganglion cells that project to the dorsal lateral geniculate nucleus in the macaque monkey. Neuroscience 1984; 12: 1101-23.

38. Porac C, Coren S. The dominant eye. Psych Bull 1976; 83(5): 880-97.

39. Ranganath C, Joe DeGutis, D’Esposito M. Category-specific modulation of inferior temporal activity during working memory encoding and maintenance. Cogn Brain Res 2004; 20(1): 37-45.

40. Rassomagina M, Kravchenko V. Electrical activity of the brain during monocular presentation of verbal stimuli in emotional Stroop-test. Vysnik of Kyiv National Taras Shevchenko University. Problems of regulation of physiological functions 2013; 16: 37-41.

41. Rombouts S, Barkhof F, Sprenger M, Valk J, Scheltens P. The functional basis of ocular dominance: Functional MRI (fMRI) finding. Neurosci Lett 1996; 221: 1-4.

42. Rozumnikova O. Gender differences in hemispheric organization during divergent thinking: an EEG investigation in human subjects. Neurosci Lett 2004; 362.

43. Spague J. Interaction of cortex and superior colliculus in mediation of visually guided behavior in the cat. Science 1966; 153: 15447.

44. Summerfield Ch, Mangels J. Coherent thetaband EEG activity predicts item-context binding during encoding. Neuroimage 2005; 24 : 692-703.

45. Toosy A, Werring D, Plant G, Bullmore E, Miller D, Thompson A. Asymmetrical activation of human visual cortex demonstrated by functional MRI with monocular stimulation. Neuroimage 2001; 14: 632-41.

46. Yuan J, Guo J, You Y. Neural oscillatory evidence of the difference between emotional and conceptual processing in language comprehension. Neurosci Lett 2013 Oct 11; 553: 159-64.

47. Van Strien J, Valstar L. The laterized emotional Stroop task: left visual field in women. Emotion 2004; 4(4): 403-9.

48. Vol'f N, Rozumnikova O. Gender differences in hemispheric spatiotemporal EEG patterns upon reproduction of verbal information. Fiziol Chelov 2004 May-Jun; 30(3): 27-34.

\section{Mariia Rassomagina, Victoria Kravchenko, Mykola Makarchuk}

\section{MONOKULIARINIAI DOMINUOJANČIOS AKIES ŽODINIŲ STIMULŲ ELEKTRO- FIZIOLOGINIAI ATSAKAI NAUDOJANT EMOCINI STROPO TESTĄ}

\section{Santrauka}

Šiame darbe buvo tirtos emocinių žodžių, pateikiamų dominuojančiai akiai, monokuliarinio atsako savybès naudojant emocinị Stropo testą. Dešiniarankiams pateikus emocinius žodžius dominuojančiai akiai, užfiksuota didesnè beta bangų galia, o taikant tokí patị testą kairiarankiams - didesnè tiek beta, tiek teta bangų galia. Neutralaus stimulo dominuojančiai akiai atveju atsakų skirtumai tarp dešiniarankių ir kairiarankių buvo neryškūs. Smegenų signalai nesiskyrè ir tuomet, kai dominuojančiai akiai buvo pateikiami prasminiai arba beprasmiai žodžiai. Tai rodo, kad informacijos, einančios per dominuojančios akies vizualinị kanalą, apdorojimo metu nereikšmingas stimulo semantinis kontekstas yra nevertinamas.

Raktažodžiai: EEG, emociniai žodžiai, dominuojanti akis, monokuliarinis atsakas 